\title{
CONFLICTO ÉTNICO Y SISTEMA LITERARIO: LA REPRESENTACIÓN DEL INDIO EN DROGUETT Y GUZMÁN ${ }^{1}$
}

\author{
Ethnic conflict and the literary system: \\ The indigenous representation in Droguett and Guzmán
}

Gerson Mora Cid*

\begin{abstract}
RESUMEN
La llamada nueva novela histórica chilena halla en los estudios críticos que la acompañan desde su consagración, a partir de los años 80 , una actitud celebratoria. Esta valoración no ha sido tan favorable al tratarse de sus predecesoras, herederas del paradigma positivista. Ciertamente, las novelas de corte decimonónico parecen no estar a la altura de los actuales proyectos multiculturales que hoy presiden el programa identitario nacional. Por contrapartida, uno de los aspectos más valorados por la crítica en las novelas más actuales es su capacidad para dar cuenta de modo más convincente de aquella pluralidad cultural. Aceptando de antemano esos razonamientos, el presente trabajo quiere subrayar como factor decisivo de esta evolución la renovación de los sistemas narrativos. La consideración de este aspecto, estudiado aquí en dos novelas pertenecientes a la tradición renovada, debe complementar una interpretación que generalmente se ha circunscrito al problema de la conciencia política de los escritores.
\end{abstract}

Palabras clave: Nueva novela histórica chilena, multiculturalidad, sistema literario.

\footnotetext{
${ }^{1}$ Este trabajo es producto del proyecto de investigación interno DIN11/14 (2011-2012), de la Universidad Católica de la Santísima Concepción: "Actualidad de la novela histórica en Chile: Carlos Droguett, el iniciador".

* Facultad de Educación, Departamento de Lenguas, Universidad Católica de la Santísima Concepción. Concepción, Chile. Correo electrónico: gmora@ucsc.cl
}

Artículo recibido el 12 de diciembre de 2013. Aceptado el 7 de abril de 2014. 


\begin{abstract}
The new Chilean historical novel finds in the critical studies that have been accompanied since its consecration, which started in the 80 's, a celebratory attitude. This appreciation has not been favorable for the novels that preceded the 60's, which inherited the positivist paradigm. Indeed, the 19th century style of novels seems not to be in an equal position than the current multicultural projects from the national identity program. One of the most valued aspects by the critic in the present-day novels is its capacity to show in a very convincing way the cultural plurality, and the acceptance of those thoughts. The present work wants to highlight as an important factor of this evolution, the renewal of the narratives systems. This aspect has been studied in two novels belonging to the renewed tradition, complementing an interpretation that, generally, has been a problem in the writers' conscience.
\end{abstract}

Keywords: The new Chilean historical novel, multicultural, literary system.

\title{
PRECISIONES INICIALES
}

El discurso de la conquista y sus reelaboraciones literarias coloniales y modernas es el objeto de una línea crítica en constante desarrollo. Uno de sus énfasis, tal vez el más significativo en volumen y profundidad, está puesto en el conflicto interétnico contenido en dicho corpus. Trivińos sintetiza perfectamente la manera en que la crítica ha estado leyendo estos textos al calificarlos como "fascinante testimonio literario del fracaso en Chile del proyecto moderno signado por la reducción del otro al prójimo" (Triviños 2004: 17). Obligado a contemplar este crimen indesmentible, el escritor situado ante el conflicto étnico, ya sea porque lo aborda directamente o porque le surge, ineludible, en un proyecto de orientación distinta, se enfrenta ante todo al desafío de plasmar en su obra dos elementos difíciles de conciliar: proyecto escritural propio y programa identitario nacional. Está claro que de tal desafío el escritor no siempre sale airoso. Es lo que ocurre, por poner un ejemplo, con la novela El mestizo Alejo, de Víctor Domingo Silva, escrita con el claro propósito de homenajear al componente mapuche de la cultura chilena, pero leída por la crítica como una obra que "perpetúa la mixtificación de la diferencia étnica" (Viu, 2007: 146). El caso de Silva no es aislado, pues de alguna manera se extiende por todas las novelas que intentaron una empresa parecida, al menos hasta la mitad del siglo XX. A partir de este momento, que coincide con un proceso de renovación de los sistemas narrativos en la novela chilena, se observa un cambio de actitud en la crítica respecto de este tipo de obras. Esta nueva valoración, perceptible ya en los escasos comentarios sobre las novelas históricas de Droguett, publicadas a partir de los ańos sesenta, se va a concretar con amplitud 
en aquellas obras que a partir de los ańos ochenta van a constituir una especie de boom del relato de alcance interétnico en Chile.

Cuando se trata de subrayar esta evolución en el abordaje literario de los conflictos étnicos, el problema del cambio de los sistemas narrativos, no obstante, pasa desapercibido. La explicación del fenómeno tiende entonces a circunscribirse al ámbito de la conciencia política de los escritores. Camino riesgoso, pues obliga a concluir que Víctor Domingo Silva es, desde el punto de vista de los proyectos identitarios actuales, no solo peor escritor, sino incluso peor chileno que Patricio Manns, por ejemplo. Es claro que una conclusión como esta resulta a lo menos curiosa. Al respecto y sobre la idea de que el corpus novelesco del cual un autor como Víctor Domingo Silva forma parte corresponde a lo que Ángel Rama (2004) comprende como formas tradicionales de la novela, es decir, aquellas que provienen de los sistemas narrativos del positivismo decimonónico, y aceptando al mismo tiempo que la extrema rigidez de dichas formas difícilmente puede plasmar de manera satisfactoria realidades interculturales complejas, es que el interés de estas líneas se encuentra más bien en mostrar hasta qué punto la superación de las visiones culturales estereotipadas depende de la renovación de los formatos narrativos. Con ese objetivo en mente, consideraremos aquí las estrategias narrativas a partir de las cuales dos novelas históricas chilenas de los últimos cincuenta años logran superar el esquematismo de las miradas tradicionales sobre la heterogeneidad cultural chilena.

Aunque se publican con más de 30 años de diferencia, las novelas consideradas en este trabajo pueden ser ubicadas en la fase más contemporánea de la novela histórica chilena ${ }^{2}$. Se trata de 100 gotas de sangre y 200 de sudor, escrita por Carlos Droguett y publicada en 1961, y de Ay, mama Inés, de Jorge Guzmán, publicada en 1993. Estas obras reconstruyen el momento fundacional de la primera conquista y en ambas encontramos, aunque con variaciones en sus grados de protagonismo y en los significados que encarnan, prácticamente a los mismos personajes: Pedro de Valdivia, Inés de Suárez o Pero Sancho de la Hoz, por nombrar algunos. El hecho de compartir esta misma materia histórica no sólo debe hacer más distinguibles las estrategias narrativas de ambas novelas. También debieran quedar perfiladas sus distintas maneras de abordar la interculturalidad. El punto neurálgico de este proceso es la representación de esta otredad cultural que esquemáticamente llamamos "india”. Este es justamente el punto a abordar en este acotado análisis.

\footnotetext{
${ }^{2}$ Han pasado 50 años desde la publicación de la primera de las obras históricas de Droguett y 70 ańos desde que fuera escrita; no obstante, la crítica identifica en ella los signos de renovación de la novela histórica chilena. Sus artificios narrativos y la mirada que ofrece van a derivar en un "proceso de desacralización de lo heroico en la nueva novela histórica, que permite la visión de lo intrahistórico, de los "trabajos" para obtener las victorias y las pesadillas de las derrotas no deseadas" (Barraza, 2004: 120).
} 


\section{NOVELA Y CONFLICTO ÉTNICO}

Si la especificidad histórico-política de una nación determina los programas identitarios contenidos en sus novelas, el escritor chileno no podrá eludir aquello que Bernardo Subercaseaux define de la siguiente manera:

A diferencia de otros países de la región, en Chile, en el caso de los mapuches, la mezcla física con indígenas que se viene dando desde la Colonia no se tradujo en un proceso activo de interculturalidad. Más bien puede afirmarse que la cultura mapuche $[\ldots]$ ha sido un ghetto y su presencia o proyección cultural en la sociedad mayor, vale decir su peso en la identidad nacional, es más bien débil o casi nulo (Subercaseaux, 2002: 33).

Si bien los discursos oficiales han demostrado hasta hoy una capacidad inalterable para mantenerse al margen de esta denuncia, la literatura ha mantenido una atención constante a este desequilibrio ${ }^{3}$. Una atención que, en todo caso, no posee un carácter unívoco, pues, como también es opinión más o menos extendida entre los estudiosos del problema, al menos hasta los años ochenta, con escritores como Patricio Manns, Jorge Guzmán o Eduardo Labarca, la novela ocupada en temas interétnicos posee un carácter idealizador de la figura del indio. Eduardo Barraza agrega que en aquellas novelas, las que van desde Blest Gana a Fernando Alegría, "predomina un discurso liberal de la Conquista de Chile", cuyo carácter "termina por anular la conflictiva diferencia de la comunidad hegemónica con su contraparte no europea, evitando de este modo dar cuenta de la constitución interétnica e intercultural de una nación” (Barraza, 2004: 60). A partir de la revisión de los trabajos de Viu y Barraza, el primero centrado en la novela histórica y el segundo, en el discurso de la conquista, queda más o menos establecida la existencia de dos momentos en el discurso de la problematización étnica de la nación chilena. El primero se iniciaría con Blest Gana y se desplegaría durante todo el resto del siglo XIX hasta alcanzar gran parte del XX, con escritores como Víctor Domingo Silva o el mismo Fernando Alegría. Sus buenas intenciones, eso sí, serían sólo aparentes y se diluirían bajo la marca de una hoy inaceptable ideología

\footnotetext{
${ }^{3}$ Esta idea se encuentra ampliamente desarrollada en los trabajos de Gilberto Trivińos. Transcribo una cita que me parece elocuente al respecto: "Hemos ido apagando entre todos, en efecto, los diamantes del español Alonso de Ercilla, pero también los de los chilenos Alberto Blest Gana y Baldomero Lillo, Pablo Neruda, Gabriela Mistral, Patricio Manns... Esos diamantes que iluminan el secreto de Galvarino en La Araucana, de Peuquilén en Mariluán, de Quilapán en Sub-Sole, de Lautaro en Canto General y Pasión y Epopeya de Halcón Ligero, de la brava-gente araucana en Poema de Chile, de José Segundo Leiva y Lautaro Leiva Allipén en Memorial de la noche..." (Triviños, 2003: 123).
} 
implícita. El segundo grupo de obras incluye los trabajos de Patricio Manns en los años 80 y continúa hasta el día de hoy con las novelas de Jorge Guzmán, Sonia Montecino y Eduardo Labarca, entre otros. La valoración que la crítica posee sobre este segundo grupo de escritores puede comprenderse, en palabras de Mauricio Ostria, como "los esfuerzos sinceros de los escritores chilenos por establecer un diálogo intercultural, por remediar el largo olvido, para hablar de peñi a peñi o de hermano a hermano con el pueblo mapuche" (Ostria, 2009: 296).

Me permito una pequeña aprehensión respecto de estas formas de valorar dichas tendencias. Como ya hemos esbozado al principio, la acusación ideológica que se hace a los textos decimonónicos puede resultar un tanto injusta si no se considera primero su capacidad para superar los horizontes estéticos disponibles en sus contextos de producción. Si estos son culpables de algo, más que de incorrección política, lo son de ser todavía devotos, incluso muy entrado el siglo XX, de un sistema literario, el realista positivista, que en Europa llevaba décadas sepultado. Por ello se puede hablar incluso de los enormes esfuerzos de aquellos novelistas por alimentar el malestar interétnico a través de unas formas literarias sencillamente inservibles para esos fines. Es también por eso que Triviños puede otorgarle a dicho corpus el carácter de canon silenciado ${ }^{4}$. Respecto de las nuevas novelas, Ostria tiene mucha razón cuando afirma que su eficacia radica "en el desplazamiento hacia tipos discursivos que devienen siempre fronterizos en procesos que los aproximan o alejan de determinaciones genéricas consabidas" (Ostria, 2009: 297), lo cual equivale a reconocer en ellas su adscripción a nuevos sistemas narrativos. No obstante, no parece tan convincente la interpretación de estas novelas como el esfuerzo por hablar de hermano a hermano con el pueblo mapuche. Dicha afirmación parece olvidar, por ejemplo, que estas novelas están escritas en español y que son parte de una forma occidental y europea de cifrar el mundo. Muestran, sin duda, una actitud política muy clara a favor de los pueblos históricamente oprimidos, pero las posibilidades que ofrece el género mismo, con todas las implicancias de su contexto sociocultural, no pueden ir más allá del intento por remecer la conciencia histórica y política del lector chileno. Sergio Caniuqueo expresa claramente la posición de los intelectuales mapuche ante este tema al señalar que de todos esos escritores:

\footnotetext{
${ }^{4}$ En el prólogo al libro de Eduardo Barraza, De La Araucana a Butamalón, propone Triviños las siguientes interrogantes: “¿Por qué recordamos el canto y olvidamos el llanto de La Araucana? ¿Por qué llamamos clásico por excelencia a La Araucana y no igualmente al Cautiverio Feliz? ¿Por qué privilegiamos Martín Rivas a expensas de Mariluán? ¿Por qué celebramos El chiflón del diablo, de Baldomero Lillo, y no Quilapán? ¿Por qué excluimos del canon, cuando no del corpus, a Testimonio de un cacique mapuche, de Pascual Cońa? ¿Por qué destacamos Eloy o Sesenta muertos en la escalera, de Carlos Droguett y no Supay, el cristiano o 100 gotas de sangre y 200 de sudor?" (Trivińos, 2004: 13-14).
} 
[...] ninguno ha analizado al mapuche en sí mismo: los ritos, ceremonias y creencias trabajadas son las que poseen vía cronistas o relatos escuchados sin profundizar en los sistemas de creencias y conocimiento mapuche. Por otro lado, su público no es el mapuche sino el winka. Ellos buscaron en ustedes despertar algo acerca de los mapuche: conocimiento, asistencialismo, en el fondo, revisar y dar una explicación a las relaciones interétnicas que se desarrollaban en el territorio mapuche (Caniuqueo, 2006: 138).

Aunque Caniuqueo se refiere a las novelas que nosotros consideramos del primer ciclo, es decir, las pertenecientes al siglo XIX y primera mitad de XX, sus aseveraciones alcanzan de algún modo a cualquier intento "winka" de acercamiento a la realidad mapuche. La mención, sin ir más lejos, del receptor para el que la obra estaría codificada parece indesmentible. Así, se puede reconocer que si bien la novela chilena considerada en este estudio hace guiños conciliadores y gestos fraternos a la comunidad mapuche, su campo de acción directo es la nación chilena -cuerpo que, eso sí, se proyecta ahora como multiétnico-y el entramado discursivo que la conforma.

¿Dónde se hallan entonces las diferencias entre estos dos corpus claramente enfrentados por la crítica si no es en su intencionalidad política? La única respuesta posible envía al problema de la elección del sistema narrativo. En ese sentido, la ineficacia de las formas literarias emanadas del realismo para incorporar cosmovisiones distintas a la fijada por el positivismo sentencia las opciones de cualquier proyecto tendiente a introducir un equilibrio étnico al interior de una cultura.

Me interesa, a partir de ahora, mostrar que el paso de las narrativas monoculturales de raíz decimonónica a los proyectos transculturados del presente no es abrupto. Entre ambas manifestaciones se interponen al menos 30 ańos en los que encontramos muy pocos proyectos novelescos que impliquen el componente étnico. De hallarlos, probablemente ninguno será tan interesante como el de Carlos Droguett. Paso a compartir algunas ideas acerca del sitial atribuible a las novelas históricas de Droguett en la renovación del sistema literario utilizado tradicionalmente por este subgénero, así como de la generación de una mirada distinta sobre el conflicto étnico de la exhibida hasta este momento por la novela chilena. Luego, a partir de la obra de Jorge Guzmán Ay, mama Inés (1993), perfecta representante de las nuevas novelas históricas chilenas, expongo otras conjeturas sobre la renovación literaria de dicho proyecto y sus alcances. 


\section{GOTAS DE SANGRE Y 200 DE SUDOR}

La obra de Droguett está instalada en la historia literaria nacional como un proyecto literario individualista y técnicamente innovador. Sus novelas más nombradas, Eloy (1957), Patas de perro (1965) o Todas esas muertes (1971), poseen un marcado acento social. Con un perfil muchísimo más bajo entre la crítica y sin segundas ediciones se encuentra la trilogía histórica del origen nacional que comprende 100 gotas de sangre y 200 de sudor (1961), Supay, el cristiano (1967) y El hombre que trasladaba las ciudades (1973). Por razones de espacio, el análisis se centra en la primera de ellas, recordando que las tres comparten estilo y estructura narrativa. Refiriéndose justamente al tipo de programa narrativo presente en Droguett, José Promis afirma que "respondió a una teoría y a una práctica discrepante no sólo de las convenciones literarias impuestas por las generaciones naturalistas, sino también de las actitudes asumidas por los primeros escritores antipositivistas" (Promis, 1993: 110). Es esta actitud discrepante de Droguett frente al programa narrativo naturalista lo que le permite proponer unos puntos de vista a partir de los cuales se despliega una manera distinta de observar los conflictos esbozados más arriba.

Llama la atención, primero, el uso de una focalización centrada exclusivamente en los españoles. Para el problema de la representación del indio este es un hecho fundamental e inédito en la narrativa chilena. Efectivamente, Mariluán, Quilapán, Alejo o el Lautaro de Fernando Alegría son intentos por retratar al indio desde sí mismo, aunque son también los intentos por traducir la incomprensible e incomprendida otredad cultural en códigos asimilables para los lectores chilenos. Droguett renuncia a ese camino, pues su proyecto no apunta a reivindicar directamente al indio sino a comprender la mentalidad del que lo ha atropellado. $\mathrm{El}$ indio plasmado en sus novelas es el indio que ven los españoles y con ello sortea la responsabilidad de construirle retratos subjetivos. Y a propósito, ¿qué puede ser más riesgoso para un novelista que intentar la verosimilitud de una cultura que le es extraña? Esta clara evasión no sería tan clara si el narrador omnisciente utilizado en sus novelas se mantuviera estrictamente anclado en la perspectiva de español. Por el contrario, muestra una gran versatilidad cuando en un pasaje de la novela, por ejemplo, llega a ofrecer el retrato subjetivo de un animal'5. Un animal y no un indio.

\footnotetext{
${ }^{5}$ Un apartado entero es el que dedica Droguett a las últimas horas de un caballo atrapado en la nieve. La perspectiva se mantiene generalmente fuera de él, pero en momentos parece ingresar a la conciencia misma del animal: "Sollozó largamente, sonó profundo, muy abajo el correr del agua, golpeó con la pezuña el suelo, que se quebró y metida le quedó la pata. La alzaba para sacarla cuando el suelo se hizo pedazos y cayó al río, sonó espantoso el desprendimiento del hielo, el caballo relinchó una y otra vez, claramente ahora. El contemplar y sentir el agua le había hecho reencontrar su instinto, braceó con fuerza en medio de la corriente y movió los remos para mantenerse a flote. Sus relinchos se azotaban en el horizonte y él los escuchaba con pavor y tristeza" (Droguett, 1961: 62).
} 
Este se mantendrá siempre mediado por la conciencia del conquistador. ¿¿Y qué es el indio para el español? Primero es una fuerza homogénea, un cuerpo unitario que se desplaza sobre el territorio sigilosamente. Es una amenaza independiente de otras, pero que, al mismo tiempo, se mimetiza en el gran telón de fondo que es el paisaje virgen. Pertenece al mismo estado de cosas que el cóndor o el invierno:

No dormían bien los espańoles, el vuelo de los cóndores les espantaba el reparador sueño. El agua del río, dulce, suave almohada de susurros, no los adormecía; el ladrido de los perros no les provocaba ese tranquilizado pavor que les cobijara el sueño, el ladrido de los perros los espantaba. ¿Viene el indio? (Droguett, 1961:29).

El relato, así construido, expone la incapacidad del conquistador para asimilar al indio como un par. Pero su estatus de fuerza natural podría todavía permitir su ubicación en el orden de lo humano, como el enemigo camuflado y sigiloso que es, si no fuera porque un proceso de cosificación actúa sobre él convirtiéndolo inclusive en eventual alimento:

- ¡Del cielo no cae la comida!

-¿Hasta cuándo?

-iMatemos a los caballos!

-¿Están locos?

-¡Sí, estamos locos!

$-¿ Y$ si viene el indio?

- ¡Que venga! ¡Si pudiéramos comer al indio!

Pero no, tampoco carne india cayó por los alrededores (Droguett, 1961:35).

El narrador, al final de la cita, se hace parte de la visión que el español despliega sobre el indio. Pero claramente no se trata de la verdadera expresión ética de la novela, sino de una estrategia discursiva, cargada de ironía, consistente en construir la perspectiva española a partir de un narrador omnisciente, desechando la opción de un narrador protagonista o testigo, elección más o menos lógica cuando se intenta la construcción de subjetividades exclusivas. El narrador utilizado por Droguett tendría un sesgo tradicionalista si no se mantuviera insistentemente apegado a los códigos psicológicos de los españoles. Por ello, en la cita, en lugar de entregar un enunciado neutro prefiere remarcar la conducta cultural del conquistador con el "tampoco carne india cayó por los alrededores", en lo que podría ser una variación del estilo indirecto libre. De este procedimiento narrativo, surge una imagen del indio liberada de toda su trascendencia histórica, de toda su carga semiótica y cultural. Reducido a puro acontecimiento en la percepción de una conciencia flagelada por la necesidad y los nervios, el indio carece en Droguett de toda individualidad. 
Eso sucede con el indio que ronda sigiloso y oculto al español. Pero no hay que olvidar a los yanaconas, quienes comparten el espacio con el invasor en calidad de bestias. No se encuentra el yanacona, sin embargo, al mismo nivel de otras bestias como el caballo o incluso el perro, tal como lo contempla la lógica del hambre con que es clasificado:

-Aquí están los yanaconas. ¡Comamos carne de esclavos!

- ¡Jamás, es sucia, hedionda, está podrida!

- ¡Tienen una carne negra, como el betún de la acequia que destapó el alarife Gamboa! ${ }_{-}^{-}$H Hasta de ratones de agua se alimentan, que son los peores! (Droguett, 1961:3839).

El estado de degradación que la perspectiva del conquistador proyecta sobre los indios tiene otras aristas, además de las ya consignadas. El texto no es ajeno al fenómeno del mestizaje, asignándole un espacio que, aunque se limita a la órbita de un solo personaje, resulta suficiente para sacar conclusiones. Juan Romero, uno de los personajes centrales del relato y quien porta mejor que ningún otro el carácter trágico de la obra -esta, de hecho, culmina con su muerte-, viola a una india y termina obsesionado con ella.

Bajó la mano por la espalda, la apretó contra su pecho, tentó los senos, eran duros, con una dureza amable y prometedora. Quiso abrir el blusón que las encerraba pero la india se movía entre gritos de pavor que se ahogaban en la boca tapada por el bigote del hombre. [...] Como se quejara, él sonrió y, besándola, la besó otra vez, mientras sentía que ella le apretaba y le entregaba las piernas (Droguett 1961:80).

Romero terminará deseando desposar a la india, convertida en el punto de fuga de su oscuro presente, que le llevará a ser ajusticiado en la horca por traición. Desde el momento recién citado, en Romero opera un proceso en el que su pasión se vuelve sentimental. Este sentimentalismo es un elemento indisociable del futuro trágico que le espera, pues también su relación con Pero Sancho de la Hoz tiene una dimensión afectiva y no sólo práctica. En el universo creado por Droguett, sólo el estadio más animal de la pulsión sexual tiene cabida como impulsor de mestizaje. Esta dimensión del conflicto étnico, es bueno precisarlo, permanece bastante disimulada en las viejas novelas, donde priman las estructuras idealizantes. En Droguett, el único personaje poseedor de una proyección idealizada con una india termina siendo sacrificado.

Hasta ahora vemos claramente cómo una técnica narrativa distanciada del sistema literario utilizado por las viejas novelas escritas entre 1850 y 1950 proyecta una visión del indio absolutamente diferente de las ofrecidas por aquellas novelas. Veamos ahora, en Ay, mama Inés, de qué manera la nueva novela chilena ha avanzado hacia una renovación de sus técnicas narrativas y, a partir de allí, a una visión distinta del problema étnico. 


\section{AY, MAMA INÉS}

Tres décadas después de la publicación de 100 gotas de sangre y 200 de sudor aparece la novela de Jorge Guzmán, Ay, mama Inés. El material histórico con el que ambas novelas trabajan es prácticamente el mismo, solo que Guzmán noveliza un lapso mucho mayor de tiempo, incluyendo, en consecuencia, muchos más acontecimientos históricamente cifrados. Mientras Droguett concentra su novela entre 1541 y 1547 , el relato de Guzmán abarca desde la concepción de la empresa de Valdivia en 1540 hasta la muerte de Inés de Suárez en 1580.

Eduardo Barraza dedica en su ya citado libro algunas páginas a la comparación de estas dos novelas, donde puede leerse lo siguiente:

En suma, en Droguett y en Guzmán, el recurso a las digresiones, a la ironía y al lenguaje coloquial no anula la omnisciencia del narrador con respecto a la historia que configura, sino que le otorga una mayor libertad para referirse a la conquista mediante sucesivos registros de habla que permiten alcanzar la desacralización y relativización del proceso de la conquista de Chile (Barraza, 2004:129).

Se hace visible que 100 gotas de sangre y 200 de sudor está mucho más cerca del grupo de nuevas novelas históricas que del grupo de orientación decimonónica. El nexo consiste, según queda explicitado en la cita, en una actitud desacralizadora ante las versiones tradicionales del origen de la nación chilena, que a su vez se encuentra articulada con el abandono de un sistema literario ortodoxo. Este es el punto en común entre dos novelas que en otros aspectos son muy distintas. Una de esas diferencias evidentes radica en sus representaciones del indio y en los significados generados por esas representaciones.

En Droguett, la representación del mapuche se proyectaba a través de la subjetividad española; en Guzmán, en cambio, vuelve a depender de la configuración directa del narrador, tal como ocurría en los viejos proyectos decimonónicos. Con la salvedad de que en Guzmán el narrador asume desde el principio una actitud relativista sobre la conquista, como dice Barraza, pero también sobre su propia función en el relato. Ese es el rol que juega el primer capítulo llamado Precisiones y realidades, que rememora irónicamente los comienzos de las antiguas crónicas de indias, donde no se concibe el despliegue del relato sin la explicitación previa del aparato ideológico que lo sostiene. Aunque no arranca con la descripción de la fisonomía del mundo, como sucede en muchas de aquellas obras, el narrador de $A y$ mama Inés sí entrega lineamientos generales sobre cómo debe tomarse el contenido de la obra: "Hasta de los hechos hay que decir aquí "parece", "no se sabe" o "es casi seguro" (Guzmán, 1993: 10). Más adelante incluirá citas de Descartes y de Engels para reafirmar interpretaciones sumarias e históricamente distanciadas 
de los sucesos que va a narrar. Desde aquí se despliega lo que Barraza denomina "perspectiva desenfadada y enfática del relato" (Barraza, 2004: 126), pero también lo que Cristián Cisternas comprende como el reemplazo de las estructuras lógicas del relato por la lógica del deseo (Cisternas, 1995).

A diferencia de lo que ocurre en 100 gotas de sangre y 200 de sudor, en $A y$, mama Inés hay un equilibrio mucho mayor entre los componentes español e indio. Esta voluntad se expresa desde el primer capítulo donde leemos: "La historia en que colgaron sus sueños personales el español y el indio no se los pudo sostener" (Guzmán, 1993: 10). Esta imagen de la historia donde hay suficiente espacio para que ambos bandos cuelguen sus sueños, sumado al hecho de que ninguno de los dos pudo sostener su proyecto, implica que la nación actual desde la cual emerge la voz del narrador, se funda sobre ambos fracasos. Repasaremos al final las implicancias de la proyección mestiza implícita en esta fórmula. Por ahora interesa mostrar que el soporte sobre el cual dicha fórmula se afianza en la novela es el de un equilibrio en los protagonismos y en las focalizaciones de los componentes étnicos enfrentados. Y a pesar de que el protagonismo de Inés implique que la balanza de la focalización se vuelque hacia el español, los indios marcan presencia desde el principio, tanto en el plano colectivo como en el individual. En el primero, Guzmán da a la colectividad mayor especificidad que Droguett, nombrándolos como "los indios", pero distinguiéndolos como "los mapochones" o "los picunches del valle del Aconcagua". En el plano individual, si en la novela de Droguett no presenciábamos el perfil de ninguna individualidad del bando mapuche, con Guzmán asistimos a una verdadera galería de ellos. El ejemplo más sobresaliente es el de Felipe, de quién se cuenta detalladamente la evolución que lo lleva de ser un indiecillo travieso a desarrollar el carácter del líder mapuche Lautaro, futuro asesino de su antiguo amo.

El día en que Valdivia sorprendió al niño montado en pelo sobre el cuatralbo de Inés, con una cuerda por rienda, estuvo a punto de ordenar que lo despellejaran a azotes. Quizá si el delincuente hubiera hecho algún movimiento de disimulo o de escape, no se habría librado del castigo, pero se quedó tranquilamente sobre el animal, sin mirar a Valdivia, pero sin amilanarse (Guzmán, 1993:194).

Es este un enfrentamiento cara a cara, aunque Felipe no mire a Valdivia. Momentáneamente despojado de la autoridad que le proporcionan sus armas y su jerarquía entre los españoles, el gran conquistador Valdivia se enfrenta al pequeño Lautaro en su propio terreno, bajo su absoluta jurisdicción, y sale derrotado. El narrador maneja esta escena para producir un enfrentamiento entre iguales, instalando un nuevo punto de equilibrio entre los oponentes, lo que es coherente con la tendencia general de la novela. 
Junto al muy desarrollado retrato de este personaje, abundan otros menores en protagonismo, pero que en conjunto equilibran bastante el horizonte étnico del relato. Los caciques Gaulaimanga y sobre todo Michimalonco son protagónicos en la secuencia del primer asalto indígena a Santiago. De este último expresa el texto: "Era dignísimo Michimalonco y de muy buen ver. De sólo mirarle la cara se notaba su inteligencia y su natural dulce y fiable. Incluso era de porte majestuoso el indio; superaba en estatura a casi todos los españoles" (Guzmán, 1993:149). Esta descripción, que parece evocar a los grandes mitificadores del indio como Ercilla o Alegría, es en realidad bastante criteriosa, resaltando rasgos que en ningún caso están reñidos con las posibilidades de lo humano.

Mucho más arriesgados son los intentos del narrador por dotar a ciertas figuras indias de cierto grado de subjetividad:

Ningún indio quiso bańarse junto a Exequiel, el esclavo negro de Valdivia; decían temerle al cuerpo negro. De los españoles se reían a escondidas. Les parecía remilgo gracioso tanto abrigo y tanto encamamiento. Les costaba mantener el respeto frente a Juan Romero, luego de la purga. Recordaban los viajes de la india auxiliar, llevando bacinicas continuamente al río (Guzmán, 1993:46).

La cita muestra a Guzmán realizando un movimiento opuesto al de Droguett: representar al español desde la perspectiva del indio. Pero el resultado de la operación no es el reverso de la de Droguett, pues no se orienta al retrato del español en su violencia exterminadora sino en la pequeñez de su cotidianidad. Se trata de un cambio radical de registro, del abandono del tono trágico que se halla presente en la generalidad de los relatos de la conquista (Droguett incluido) y de la asunción de un tono menos monumental, menos grandilocuente, más humano e inclusivo.

Para la novela de Guzmán son perfectamente aplicables las palabras con que Seymour Menton describe el accionar de otra gran novela histórica. Se trata de Noticias del imperio (1987), de Fernando del Paso, apenas cinco años anterior a $A y$, mama Inés. Dice Menton que aquella novela "puede apreciarse mejor en términos de su sinfonía bajtiniana: una combinación de lo dialógico o lo polifónico, la heteroglosia, lo carnavalesco y la intertextualidad" (Menton, 1993: 129). Sabido es que en Latinoamérica estas características las adquiere la novela sólo a partir de los precursores del boom. A partir de Carpentier, dirá Menton. En Droguett, algunas de estas características, principalmente la dimensión carnavalesca, están rigurosamente ausentes; en tanto que la polifonía sólo se da entre personajes del mismo bando cultural. En Guzmán, en cambio, la polifonía es más rica pues involucra el diálogo de componentes culturalmente diversos. Al mismo tiempo, un proceso de carnavalización se despliega desde el narrador, afectando a la totalidad 
del relato. De las expectativas de los indios sobre los españoles, cuenta el narrador que deseaban expulsarlos "y luego aniquilar las ciudades españolas de más al norte, los semilleros de donde provenían los cabalgantes barbudos que les culiaban a las mujeres" (Guzmán, 1993:12). Este solo gesto irreverente, parte de una actitud presente a lo largo de toda la novela, impone una distancia considerable entre esta praxis narrativa y la del pasado.

\section{CONSIDERACIONES FINALES}

En Chile, Droguett es el primer gran innovador de la novela histórica. El trabajo desplegado en su trilogía sobre el origen de la nación chilena lo coloca en el umbral mismo de la nueva novela histórica latinoamericana, exhibiendo una narratividad con aspectos que aun hoy resultan novedosos. Su insistencia en la narración sumaria, su impecable construcción monofocal de la perspectiva española y un realismo grotesco centrado en la materialidad del sufrimiento humano son fundamentos de una propuesta discursiva que después de cincuenta años continúa siendo atractiva. En tanto, el marcado tono trágico (por lo mismo, sublime) predominante en el relato, que a su vez elimina cualquier corrosión irónica, reduce sus posibilidades interpretativas, alejándolo de las formas novelescas más actuales.

La luz que la novela de Droguett dirige al conflicto étnico nacional es, como hemos visto, indirecta, pues su verdadero objeto es el surgimiento del Estado, el nacimiento de la ciudad, como lo dice él mismo en el prólogo. En ese escenario, Droguett ha tenido la capacidad de imponerle a una materia altamente codificada como lo es la guerra de conquista un programa propio, que no se interesa en mostrar cómo unos intrusos asesinan y destruyen la cultura de unos inocentes, sino a intentar dilucidar hasta dónde se remonta la extendida costumbre chilena de asesinar a quienes desafían al poder. El retrato del indio funciona aquí como un intensificador de la ceguera del conquistador, así como de su carácter estoico y despiadado. Al mismo tiempo, exponer la incapacidad del español para concebir al indio como un igual, implica evidenciar las razones de la casi nula participación mapuche en el proyecto nacional instaurado desde entonces.

Guzmán, en cambio, ha escrito una novela donde la tesis fundamental es conformación interétnica de la nación chilena. Su fórmula consiste en intentar primero un equilibrio narrativo de ambos polos, entre los cuales instala como el gran factor mestizo a la figura femenina de Inés. Niall Binns observa tres procedimientos en la novela histórica de hoy, uno de los cuales consiste en "la escritura de una historia apócrifa, que viole la historia oficial (historia de los vencedores y los hombres), no sólo complementándola mediante el relleno de sus zonas oscuras (al escribir la historia de los vencidos y mujeres), sino desplazándola y contradiciéndola totalmente" (Binns, 1996: 160). Nos parece que ese 
es justamente el sentido específico del protagonismo femenino con que Guzmán explora el momento originario de la nación. Como el foco de atención se ha desviado hacia este eje materno, la incorporación del indio y su representación dejan de ser un problema insoluble, precisamente porque desde el lugar inclusivo de la madre, la intolerancia y la expulsión se neutralizan. La fuerza de lo materno llega incluso a borrar las diferencias entre lo español y lo indio en el propio cuerpo de Inés. Cuando en un momento avanzado de la novela y luego de haber sufrido incontables calamidades encuentra Inés un estado de paz y resignación benigna, el texto expresa: "Se había aindiado y endurecido Inés, y pasaba sus reglas tranquilamente cambiándose ropa y hasta lavándose, lo mismo que las indias" (Guzmán, 1993:212). A través de la figura femenina, Jorge Guzmán logra producir imágenes del polo indio y del polo español que se articulan en el seno de la misma identidad. Así, la casa (y la protección de Inés) se convierte en ese espacio único en el que el primer gran gobernador de Chile, Pedro de Valdivia, ha podido gozar de la pasión y del descanso, y en el que su asesino, Lautaro, ha sido querido y educado.

\section{REFERENCIAS}

Barraza, Eduardo. De La araucana a Butamalón. El discurso de la conquista y el canon de la literatura chilena. Valdivia: Estudios Filológicos, Anejo 17, 2004.

Binns, Niall. "La novela histórica hispanoamericana en el debate posmoderno". En José Romera, Francisco Gutiérrez y Mario García (comps.), La novela histórica a finales del siglo XX. Madrid: Visor, (1996): 159-166.

Caniuqueo, Sergio. "Siglo XX en Gulumapu: De la fragmentación del Wallmapu a la unidad nacional mapuche. 1880 a 1978”. En Pablo Marimán et al., i... Escucha, winka...! Cuatro ensayos de Historia Nacional Mapuche y un epilogo sobre el futuro. Santiago de Chile: LOM, (2006): 129-217.

Cisternas, Cristián. "Ay, mama Inés, de Jorge Guzmán: La madre y el deseo como historia", Revista Chilena de Literatura 46 (1995): 97-100.

Droguett, Carlos. 100 gotas de sangre y 200 de sudor. Santiago de Chile: Zigzag, 1961.

Guzmán, Jorge. Ay, mama Inés. Santiago de Chile: Andrés Bello, 1993.

Menton, Seymour. La nueva novela histórica de la América Latina. México: FCE, 1993. 
Ostria Mauricio. "En busca del otro (mapuche) que somos en tres novelas chilenas contemporáneas", Revista de crítica literaria latinoamericana XXXV/69. Lima-Hanover, (2009): 295-304.

Promis, José. La novela chilena del último siglo. Santiago de Chile: La Noria, 1993.

Rama, Ángel. Transculturación narrativa en América Latina. México: Siglo XXI, 2004.

Subercaseaux, Bernardo. Nación y cultura en América Latina. Santiago de Chile: LOM, 2002.

Triviños, Gilberto. "Sigue diciendo: Cayeron -di más: Volverán mañana”, Atenea 487 (2003): 113-133.

Triviños, Gilberto. "El crimen imperfecto". Prólogo al libro de Eduardo Barraza. De La araucana a Butamalón. El discurso de la conquista y el canon de la literatura chilena. Valdivia: Estudios Filológicos, Anejo 17, (2005): 11-19.

Viu, Antonia. Imaginar el pasado, decir el presente. La novela histórica chilena (19852003). Santiago de Chile: RIL, 2007. 